E. Kousta $\cdot$ Z. Efstathiadou $\cdot$ N. J. Lawrence $\cdot$

J. A. R. Jeffs · I. F. Godsland - S. C. Barrett •

C. J. Doré • A. Penny • V. Anyaoku • B. A. Millauer •

E. Cela $\cdot$ S. Robinson $\cdot$ M. I. McCarthy $\cdot$ D. G. Johnston

\title{
The impact of ethnicity on glucose regulation and the metabolic syndrome following gestational diabetes
}

Received: 24 May 2005 / Accepted: 30 August 2005 / Published online: 9 December 2005

(C) Springer-Verlag 2005

\begin{abstract}
Aims/hypothesis: We assessed the impact of ethnic origin on metabolism in women following gestational diabetes mellitus (GDM). Materials and methods: Glucose regulation and other features of the metabolic syndrome were studied at 20.0 (18.2-22.1) months (geometric mean $[95 \% \mathrm{CI}])$ post-partum in women with previous GDM (185 European, 103 Asian-Indian, 80 African-Caribbean). They were compared with the same features in 482 normal control subjects who had normal glucose regulation during and following pregnancy. Results: Impaired glucose regulation or diabetes by WHO criteria were present in $37 \%$ of women with previous GDM (diabetes in 17\%), especially in those of African-Caribbean and Asian-Indian origin (50 and $44 \%$, respectively vs $28 \%$ in European, $p=0.009$ ). BMI, waist circumference, diastolic blood pressure, fasting triglyceride and insulin levels, and insulin resistance by homeostatic model assessment (HOMA), were increased following GDM ( $p<0.001$ for all, vs control subjects).
\end{abstract}

\author{
E. Kousta $\cdot$ Z. Efstathiadou $\cdot$ N. J. Lawrence $\cdot$ J. A. R. Jeffs \\ I. F. Godsland · A. Penny · V. Anyaoku · B. A. Millauer · \\ S. Robinson · M. I. McCarthy · D. G. Johnston ( $\bowtie)$ \\ Section of Endocrinology and Metabolic Medicine, \\ Imperial College London, \\ St Mary's Hospital Norfolk Place, \\ W2 1PG, London, UK \\ e-mail: d.johnston@imperial.ac.uk \\ Tel.: +44-20-78861209 \\ Fax: +44-20-78861790 \\ E. Cela \\ Reproductive Science and Medicine, \\ Imperial College London, St Mary's Hospital, \\ London, UK \\ S. C. Barrett · C. J. Doré \\ Epidemiology and Public Health, \\ Imperial College London, St Mary's Hospital, \\ London, UK \\ M. I. McCarthy \\ Diabetes Research Laboratories, \\ Oxford Centre for Diabetes, \\ Endocrinology and Metabolism, \\ Churchill Hospital, Headington, \\ Oxford, UK
}

Where glucose regulation was normal following GDM, basal insulin secretion (by HOMA) was high ( $p<0.001$ vs control subjects). Irrespective of glucose regulation in pregnancy, Asian-Indian origin was associated with high triglyceride and low HDL cholesterol levels, and AfricanCaribbean with increased waist circumference, blood pressure, and insulin levels, together with insulin resistance and low triglyceride concentrations. Nonetheless, the GDMassociated features were consistent within each ethnic group. The metabolic syndrome by International Diabetes Federation criteria was present in $37 \%$ of women with previous GDM, especially in non-Europeans (Asian-Indian $49 \%$, African-Caribbean 43\%, European 28\%, $p=0.001$ ), and in $10 \%$ of controls. Conclusions/interpretation: Following GDM, abnormal glucose regulation and the metabolic syndrome are common, especially in non-European women, indicating a need for diabetes and cardiovascular disease prevention strategies.

Keywords Ethnicity - Gestational diabetes - Glucose tolerance $\cdot$ Metabolic syndrome $\cdot$ Type 2 diabetes

\begin{abstract}
Abbreviations AG: abnormal glucose regulation postpartum $\%$ B: beta cell function - BP: blood pressure . $\%$ S: insulin sensitivity - GDM: gestational diabetes mellitus - HOMA: homeostatic model assessment - IDF: International Diabetes Federation - NG: normal glucose regulation post-partum - pGDM: previous gestational diabetes mellitus
\end{abstract}

\section{Introduction}

Subjects with the metabolic syndrome are at increased risk of cardiovascular disease and diabetes [1]. Gestational diabetes mellitus (GDM) is defined as hyperglycaemia first recognised during pregnancy, and although glucose regulation usually returns to normal following delivery, features of the metabolic syndrome may be present and glucose tolerance often deteriorates with time [2]. Reports on metabolism following GDM have shown variable results [3], 
and we hypothesised that this variability reflected ethnic heterogeneity in different studies, small subject numbers and different times between the index pregnancy and study. We therefore examined glucose regulation and metabolism in a large group of women from three ethnic groups, within 1 to 3 years of GDM pregnancy. They were compared with women who had normal glucose regulation during and after pregnancy.

\section{Subjects, materials and methods}

Subjects Between 1997 and 1999 we retrospectively recruited 368 women with previous GDM (pGDM) from West London databases. Recruitment was at 20.0 months (geometric mean, 95\% CI 18.2-22.1 months) following delivery. Entry was based on WHO criteria for glucose intolerance during pregnancy [4], and on the women being of European ( $n=185)$, Asian-Indian (India, Pakistan, Bangladesh or Sri Lanka, $n=103)$ or African-Caribbean $(n=80)$ ethnicity.

As controls we recruited 482 normal women at 21.6 (20.0-23.4) months after the index pregnancy. Their entry criteria were: normal glucose levels throughout the index (and other) pregnancies, normal fasting glucose and $\mathrm{HbA}_{1} \mathrm{c}$ at recruitment and European $(n=288)$, AsianIndian $(n=99)$ or African-Caribbean $(n=95)$ ethnicity as specified above.

Ethical approval was from the UK Multicentre Research Ethics Committee and local ethical committees and informed consent was obtained.

Tests performed Anthropometry was assessed and resting BP, fasting lipids and specific insulin were measured. Biochemical assays were performed as described previously [5]. Of the women with pGDM, 227 out of $368(62 \%)$ underwent a 75-g OGTT and the remainder (including 37 with known type 2 diabetes) had measurement of fasting glucose and $\mathrm{HbA}_{1} \mathrm{c}$. The pGDM group was subdivided into two: pGDM with normal glucose regulation post-partum $(\mathrm{NG})$ and $\mathrm{pGDM}$ with abnormal glucose regulation post-partum (AG) [4]. Beta cell function (\%B) and insulin sensitivity $(\% \mathrm{~S})$ were derived using homeostatic model assessment (HOMA) [6].

The metabolic syndrome was defined by International Diabetes Federation (IDF) guidelines [7].

Statistical analysis Data are presented as means $(95 \% \mathrm{CI})$ or, where log transformed, as geometric means $(95 \% \mathrm{CI})$. The prevalence of abnormal glucose regulation by ethnic group was compared by the $\chi^{2}$ test.

To determine the relationship between individual metabolic syndrome features and history of GDM, multiple linear regression models were used, with adjustment for age, parity, time between delivery and study and ethnicity. Regression models were used to study the effect of ethnicity, adjusting also for glucose regulation. For outcomes that did not require log transformation, results are reported as regression coefficients. When logarithmic transforma- tion was necessary, regression coefficients are reported as percentage changes. For ethnic comparisons, Europeans were the reference population. In view of the multiple comparisons, and in order to concentrate on differences of potential clinical importance, we adopted a stringent significance threshold $(p \leq 0.001)$.

\section{Results}

Glucose regulation and the metabolic syndrome following GDM The age of the pGDM group (geometric mean [95\% CI] 35.7 [35.2-36.2] years) was similar to controls (34.8 [34.3-35.3] years), as was the time between study and delivery. pGDM women were of higher parity (2.1 [2.0 $2.2]$ vs $1.8[1.7-1.9] ; p<0.001)$.

Of the 368 women with pGDM, 137 (37\%) at the time of study had abnormal glucose levels (diabetes $[n=62$, including 37 with known diabetes], impaired glucose tolerance [ $n=51]$, or impaired fasting glycaemia [ $n=24]$ ). Normal fasting glycaemia was as common among the 227 women with pGDM who had an OGTT $(87 \%)$ as in the 104 who did not $(81 \%)$.

There was no difference in age, or in time between pregnancy and study, between the pGDM subgroups (i.e. pGDM-NG vs pGDM-AG), although the latter were of higher parity $(2.4[2.1-2.6]$ vs $1.9[1.8-2.1] ; p<0.001)$

IDF-defined metabolic syndrome was observed in $37 \%$ of women with pGDM and $10 \%$ of controls. Women with pGDM had higher BMI and waist circumference, systolic and diastolic BP and fasting triglyceride than controls (Table 1). The differences in total and HDL cholesterol did not achieve the required significance level. Fasting glucose was increased, insulin levels were almost double and HOMA \%S almost half those in controls (both $p<0.001$ ). The two groups did not differ significantly in HOMA $\% \mathrm{~B}$ $(p=0.25)$.

Differences between pGDM-NG and control women were similar to those in the entire pGDM group (except systolic BP). The pGDM-NG women had elevated HOMA $\% \mathrm{~B}$.

Women with pGDM-AG had higher BMI and waist circumference than pGDM-NG women. These groups differed in beta cell function (HOMA \%B) rather than insulin sensitivity (HOMA \%S).

Additional adjustment for BMI had little impact. Apart from systolic and diastolic BP when comparing pGDM subjects with controls, and diastolic BP when comparing the pGDM-NG with controls, other statistically significant differences persisted. Exclusion of the 37 women with known diabetes resulted in loss of statistical significance in BMI and waist circumference between pGDM-AG and pGDM-NG, but other differences persisted.

Ethnic influences on metabolism Compared with Europeans, Asian-Indian women were slightly younger and had higher triglyceride and lower HDL cholesterol; AfricanCaribbean women had higher BMI, waist circumference, systolic and diastolic BP and lower fasting triglyceride 
Table 1 The features of the metabolic syndrome among women with a history of gestational diabetes mellitus (GDM)

\begin{tabular}{|c|c|c|c|c|c|c|c|}
\hline & \multirow{2}{*}{$\begin{array}{l}\text { Control women } \\
(n=482)\end{array}$} & \multicolumn{6}{|c|}{ Women with previous GDM (pGDM) } \\
\hline & & $\begin{array}{l}\text { All pGDM } \\
(n=368)\end{array}$ & $\begin{array}{l}\text { All pGDM } \\
\text { vs controls }\end{array}$ & $\begin{array}{l}\text { pGDM-NG } \\
(n=231)\end{array}$ & $\begin{array}{l}p \text { for } \\
\text { pGDM-NG } \\
\text { vs controls }\end{array}$ & $\begin{array}{l}\text { pGDM-AG } \\
(n=137)\end{array}$ & $\begin{array}{l}p \text { for } \\
\text { pGDM-NG } \\
\text { vs pGDM- } \\
\text { AG }(n=231)\end{array}$ \\
\hline $\operatorname{BMI}\left(\mathrm{kg} / \mathrm{m}^{2}\right)^{*}$ & $24.5(24.1-24.9)$ & $27.5(26.9-28.1)$ & $<0.0001$ & $26.5(25.8-27.2)$ & $<0.0001$ & $29.3(28.2-30.5)$ & 0.0001 \\
\hline $\begin{array}{l}\text { Waist } \\
\text { circumference } \\
(\mathrm{cm})\end{array}$ & $79.6(78.6-80.6)$ & $89.1(87.6-90.5)$ & $<0.0001$ & $86.4(84.8-88.1)$ & $<0.0001$ & $93.5(90.7-96.2)$ & 0.0002 \\
\hline $\begin{array}{l}\text { BP systolic } \\
(\mathrm{mmHg})^{*}\end{array}$ & $111(110-113)$ & $116(114-118)$ & $<0.0001 \uparrow$ & $114(112-116)$ & 0.01 & $118(115-122)$ & 0.06 \\
\hline $\begin{array}{l}\text { BP diastolic } \\
(\mathrm{mmHg})^{*}\end{array}$ & $70(69-71)$ & $73(72-75)$ & $<0.0001 \dagger$ & $74(72-75)$ & $0.0001 \dagger$ & $73(71-76)$ & 0.66 \\
\hline $\begin{array}{l}\text { Fasting cholesterol } \\
(\mathrm{mmol} / \mathrm{l})^{* *}\end{array}$ & $4.6(4.5-4.7)$ & $4.9(4.8-5.0)$ & 0.0012 & $4.8(4.7-5.0)$ & 0.01 & $4.9(4.8-5.1)$ & 0.61 \\
\hline $\begin{array}{l}\text { Fasting HDL } \\
\text { cholesterol } \\
(\mathrm{mmol} / \mathrm{l})\end{array}$ & $1.2(1.2-1.3)$ & $1.2(1.2-1.2)$ & 0.04 & $1.2(1.2-1.3)$ & 0.80 & $1.1(1.1-1.2)$ & 0.02 \\
\hline $\begin{array}{l}\text { Fasting triglycerides } \\
(\mathrm{mmol} / \mathrm{l})^{*}\end{array}$ & $0.9(0.8-0.9)$ & $1.2(1.2-1.3)$ & $<0.0001$ & $1.2(1.1-1.2)$ & $<0.0001$ & $1.4(1.2-1.5)$ & 0.003 \\
\hline $\begin{array}{l}\text { Fasting glucose } \\
(\mathrm{mmol} / \mathrm{l})^{*}\end{array}$ & $4.6(4.6-4.7)$ & $5.6(5.4-5.7)$ & $<0.0001$ & $5.0(4.9-5.1)$ & $<0.0001$ & $6.8(6.4-7.3)$ & 0.0001 \\
\hline $\begin{array}{l}\text { Fasting insulin } \\
(\mathrm{pmol} / \mathrm{l})^{*}\end{array}$ & $65(58-73)$ & $126(112-141)$ & $<0.0001$ & $119(103-139)$ & $<0.0001$ & $137(114-167)$ & 0.31 \\
\hline $\begin{array}{l}\text { Beta cell } \\
\text { function HOMA } \\
\text { algorithm }(\% \mathrm{~B})^{*}\end{array}$ & $137(127-148)$ & $154(141-168)$ & 0.25 & $178(161-196)$ & 0.0001 & $119(102-140)$ & 0.0001 \\
\hline $\begin{array}{l}\text { Insulin sensitivity } \\
\text { HOMA } \\
\text { algorithm }(\% \mathrm{~S})^{*}\end{array}$ & $74(66-82)$ & $38(34-43)$ & $<0.0001$ & $41(35-47)$ & $<0.0001$ & $34(28-41)$ & 0.17 \\
\hline
\end{tabular}

$p G D M-N G$ pGDM women with normal glucose regulation post-partum, $p G D M-A G$ pGDM women with abnormal glucose regulation post-partum

All other are presented as arithmetic means and 95\% CIs for the arithmetic mean

The significance levels shown are from multiple regression analysis, after adjusting for ethnicity, age, parity and time between delivery and screening

*Log-transformed in main analysis, values are geometric means with $95 \% \mathrm{CI}$

$\dagger$ Statistical significance was lost $(p>0.001)$ after also adjusting for BMI

(Table 2). Insulin was higher and HOMA \%S lower. When women with known diabetes were excluded, statistical significance in the comparison between European and African Caribbean women was lost for insulin $(p=0.005)$ but other ethnic differences persisted.

Among the 137 pGDM women with abnormal glucose regulation, 52 were Europeans (28\%), 45 Asian-Indians (44\%), and 40 African-Caribbeans (50\%). The prevalence of abnormal glucose values of any degree in both AsianIndian and African-Caribbean pGDM women was higher than in Europeans $\left(\chi^{2}=14.01, p=0.009\right)$. The prevalence of type 2 diabetes following GDM was also higher in both Asian-Indian (26\%) and African-Caribbean women $(22 \%)$ than in European women $(10 \%)\left(\chi^{2}=13.95, p=0.001\right)$.

Of the 136 pGDM women with IDF-defined metabolic syndrome, $49 \%$ were of Asian-Indian origin, $43 \%$ were
African-Caribbean and $28 \%$ were European $\left(\chi^{2}=13.4\right.$, $p=0.001$ ).

To establish whether the relationship between metabolic syndrome features and glucose regulation status (previous and current) was similar in the different ethnic groups, we sought statistical interactions between ethnicity and glycaemic status. There were no significant interactions between ethnicity and pGDM/control or pGDM-NG/ pGDM-AG status. Borderline interactions between pGDM/ control status and ethnicity were observed for fasting insulin $(p=0.0012)$, glucose $(p=0.008)$ and HOMA $\% \mathrm{~S}$ $(p=0.0014)$. pGDM-associated relative differences in BMI, waist circumference, BP and triglyceride were consistent across the ethnic groups, even though absolute values varied by ethnic origin. On further analysis of the borderline interactions, fasting insulin in the Asian-Indian women 
Table 2 Consequences of ethnic origin on the features of the metabolic syndrome and on the sequelae of previous gestational diabetes mellitus (pGDM)

\begin{tabular}{|c|c|c|c|c|c|c|}
\hline & \multicolumn{2}{|l|}{ European women } & \multicolumn{2}{|c|}{ Asian-Indian women } & \multicolumn{2}{|c|}{ African-Caribbean women } \\
\hline & $\begin{array}{l}\text { pGDM } \\
(n=185)\end{array}$ & $\begin{array}{l}\text { Controls } \\
(n=288)\end{array}$ & $\begin{array}{l}\text { pGDM } \\
(n=103)\end{array}$ & $\begin{array}{l}\text { Controls } \\
(n=99)\end{array}$ & $\begin{array}{l}\text { pGDM } \\
(n=80)\end{array}$ & $\begin{array}{l}\text { Controls } \\
(n=95)\end{array}$ \\
\hline Age (years) & $36.5(35.8-37.3)$ & $36.2(35.6-36.9)$ & $36.0(35.0-37.1)$ & $32.4(31.3-33.5) \dagger$ & $34.9(33.9-35.9)$ & $35.2(34.1-36.2)$ \\
\hline $\begin{array}{l}\text { Waist } \\
\text { circumference* }\end{array}$ & $87.8(85.5-90.2)$ & $77.7(76.6-78.9)$ & $87.5(85.4-89.7)$ & $79.8(77.4-82.1)$ & $93.9(91.0-96.8)$ & $84.9(82.6-87.3) \ddagger$ \\
\hline $\begin{array}{l}\text { BP diastolic } \\
(\mathrm{mmHg})^{*}\end{array}$ & $72(70-74)$ & $69(67-70)$ & $72(70-74)$ & $69(66-71)$ & $78(74-82)$ & $74(72-77)+$ \\
\hline $\begin{array}{l}\text { Fasting cholesterol } \\
(\mathrm{mmol} / \mathrm{l})\end{array}$ & $5.0(4.8-5.1)$ & $4.6(4.5-4.7)$ & $4.9(4.7-5.1)$ & $4.7(4.6-4.9)$ & $4.6(4.4-4.8)$ & $4.6(4.4-4.8)$ \\
\hline $\begin{array}{l}\text { Fasting glucose } \\
(\mathrm{mmol} / \mathrm{l})\end{array}$ & $5.4(5.2-5.6)$ & $4.7(4.6-4.7)$ & $5.9(5.6-6.2)$ & $4.6(4.5-4.7)$ & $5.8(5.4-6.2)$ & $4.6(4.5-4.7)$ \\
\hline $\begin{array}{l}\text { Fasting insulin } \\
(\mathrm{pmol} / \mathrm{l})\end{array}$ & $102(88-121)$ & $66(58-76)$ & $145(117-179)$ & $44(33-60)$ & $164(126-214)$ & $90(70-116) \ddagger$ \\
\hline $\begin{array}{l}\text { Beta cell function } \\
\text { HOMA algorithm } \\
(\% \mathrm{~B})\end{array}$ & $146(129-165)$ & $137(125-151)$ & $154(131-180)$ & $108(89-131)$ & $177(144-216)$ & $175(147-207)$ \\
\hline $\begin{array}{l}\text { Insulin sensitivity } \\
\text { HOMA algorithm } \\
(\% \mathrm{~S})\end{array}$ & $46(39-54)$ & $72(63-82)$ & $33(27-40)$ & $107(79-143)$ & $31(23-40)$ & $53(42-68) \div$ \\
\hline
\end{tabular}

Women of Asian-Indian and of African-Caribbean descent were compared with European women in multiple regression analysis (including both pGDM and controls), after adjusting for age, parity and time between delivery and screening and glucose regulation status Data were transformed, or not, as in Table 1 and are presented as in Table 1

*The significant differences between pGDM and controls in BMI, waist circumference, systolic and diastolic blood pressure and triglyceride levels seen in Table 1 were consistent in the three ethnic groups $(p<0.001)$, as evidenced by the lack of interactions between ethnicity and pGDM status in the multiple regression model. For glucose, insulin and HOMA \%S, there was some evidence, at borderline significant levels $(p=0.008, p=0.0012, p=0.0014$, respectively) that the relationship between pGDM vs control status and the outcome variables was influenced by ethnicity

$\dagger$ Comparison of Asian-Indian vs European women significant $(p<0.001)$

$\ddagger$ Comparison of African-Caribbean vs European women significant $(p \leq 0.001)$

with pGDM was higher than expected from the main effects attributable to ethnicity or pGDM status $(p<0.001)$, and HOMA $\% \mathrm{~S}$ was lower $(p<0.001)$.

\section{Discussion}

This study of 850 women with young children involved certain compromises, e.g. only fasting samples, rather than an OGTT, were obtained in $32 \%$ of the pGDM women, and GDM screening policies differed between centres. However, all pGDM patients had fulfilled WHO criteria during pregnancy, and the women who had an OGTT subsequently had similar fasting glucose levels to those who did not.
The high prevalence of abnormal glucose regulation following GDM (37\%) is similar to other studies of equivalent follow-up [2]. Metabolic syndrome features were equally common. They have been observed in other situations of high diabetes risk, e.g. polycystic ovary syndrome, and they precede diabetes in prospective studies [8].

Women with previous GDM and abnormal glucose homeostasis had reduced beta cell function, but those with normoglycaemia post-partum had high basal insulin secretion (by HOMA \%B). Thus although insulin resistance is ubiquitous, hyperglycaemia post-partum reflects the inability to mount an adequate insulin response. Nonetheless, in a subset of women with normoglycaemia post-partum, we have detected subtle beta cell deficiency using an i.v. glucose challenge (5). 
Asian-Indian women had an adverse lipid profile compared with Europeans, irrespectively of glucose regulation. They were not significantly insulin resistant, but those with pGDM had higher than expected insulin levels. These ethnic differences are unlikely to reflect merely the younger age of the Asian-Indian women as the difference was small (2-3 years) and the statistical analysis was adjusted for age. African-Caribbean women were heavier than Europeans and had increased waist circumference. They were insulin resistant and had higher BP and lower triglyceride levels. These ethnic differences are similar to previous reports, mostly from studies in men [9].

Within each ethnic group, features associated with pGDM were consistent. WHO-defined abnormal glucose regulation following GDM was most common in nonEuropean women, as in some previous studies [10]. IDFdefined metabolic syndrome was also most common in non-Europeans. These features may have preceded pregnancy and suggest that non-European women with pGDM are at the highest risk of developing cardiovascular disease and diabetes. The metabolic syndrome was present in a high proportion $(43 \%)$ of the African-Caribbean women even though the IDF definition takes account of ethnic differences in waist circumference. Given that diabetes and cardiovascular disease may be prevented by lifestyle modification and/or drug therapy, prevention strategies may be especially important for non-European women.

Acknowledgements This study was funded by the UK Medical Research Council and Diabetes UK. J. A. R. Jeffs and I. F. Godsland were supported by the Heart Disease and Diabetes Research Trust.

\section{References}

1. Eckel RH, Grundy SM, Zimmet PZ (2005) The metabolic syndrome. Lancet 365:1415-1428

2. O'Sullivan JB (1991) Diabetes mellitus after GDM. Diabetes 40(Suppl 2):131-135

3. Ben-Haroush A, Yogev Y, Hod M (2004) Epidemiology of gestational diabetes mellitus and its association with type 2 diabetes. Diabet Med 21:103-113

4. Report of The World Health Organization (1999) Definition, diagnosis and classification of diabetes mellitus and its complications. The World Health Organization

5. Kousta E, Lawrence NJ, Godsland IF et al (2003) Insulin resistance and $\beta$-cell dysfunction in normoglycaemic European women with a history of gestational diabetes. Clin Endocrinol 59:289-297

6. Matthews DR, Hosker JP, Rudenski AS, Naylor BA, Treacher DF, Turner RC (1985) Homeostasis model assessment: insulin resistance and beta-cell function from fasting plasma glucose and insulin concentrations in man. Diabetologia 28:412-419

7. Alberti KG, Zimmet P, Shaw J (2005) The metabolic syndrome-a new worldwide definition. Lancet 366:1059-1062

8. Robinson S, Henderson AD, Gelding SV et al (1996) Dyslipidemia is associated with insulin resistance in women with polycystic ovaries. Clin Endocrinol 44:277-284

9. Zoratti R, Godsland IF, Chaturvedi N, Crook D, Stevenson JC, McKeigue PM (2000) Relation of plasma lipids to insulin resistance, non-esterified fatty acid levels and body fat in men from three ethnic groups: relevance to variation in risk of diabetes and coronary disease. Metabolism 49:245-252

10. Sinha B, Brydon P, Taylor RS, Hollins A, Munro A, Jenkins D, Dunne F (2003) Maternal ante-natal parameters as predictors of persistent post-natal glucose intolerance: a comparative study between Afro-Caribbeans, Asians and Caucasians. Diabet Med $20: 382-386$ 